\title{
KANT E O ESCLARECIMENTO COMO ESTRATÉGIA POLÍTICA PARA A EDUCAÇÃO DA HUMANIDADE
}

\section{Marcos César Seneda*}

A ideia de universidade em Kant tem de ser abordada desde a perspectiva de sua filosofia política (V. ROHDEN, 2002, p. 36).

Resumo: Esse texto procura investigar a seguinte questão: como pode ser conduzido um processo de Esclarecimento que não seja apenas individual, mas social e político? Uma resposta para esta questão pode ser obtida na medida em que concebemos o conceito de autonomia como fundamento da estratégia do Esclarecimento, que aqui será compreendido como um processo arquetípico de educação da humanidade. Nosso objetivo é mostrar que a proposta de educação elaborada por Kant tem de ser compreendida de um ponto de vista cosmopolita.

Palavras-chaves: Autonomia. Esclarecimento. Faculdade Inferior. Faculdades Superiores. Esfera pública.

Resumen: Este trabajo tiene por objeto investigar la siguiente pregunta: ¿Cómo puede llevarse a cabo un proceso de Esclarecimiento que no es sólo individual, sino social y político? Una respuesta a esta pregunta se puede obtener a la medida en que concebimos el concepto de autonomía como fundamento de la estrategia de la Ilustración, que aquí se entiende como un proceso arquetípico de la educación de la humanidad. Nuestro objetivo es mostrar que la propuesta de la educación elaborada por Kant tiene que ser entendida desde un punto de vista cosmopolita.

Palabras claves: Autonomía. Esclarecimiento. Facultad inferior. Facultades superiores. Esfera pública.

Este texto procura pensar Kant não como um pensador que pôde, por seus próprios desígnios, escolher livremente o modo de refletir sobre os problemas que instigavam seu intelecto, mas como um perspicaz estrategista, que teve de

\footnotetext{
${ }^{*}$ Professor Adjunto do Instituto de Filosofia (IFILO) e do Programa de Pós-graduação (PPGFIL) da Universidade Federal de Uberlândia. E-mail: mseneda@ufu.br.
}

SENEDA, Marcos César. Kant e o Esclarecimento como estratégia política para a educação a humanidade. Revista Sul-Americana de Filosofia e Educação. Número 19: nov/2012abr/2013, p. 89-102. 
situar sua reflexão em meio a pessoas, instituições e correlações de poder complexas, de tal modo que essa reflexão pudesse não somente ser dotada de fundamentos, mas também de eficácia. Portanto, os dois textos escolhidos - "O conflito das Faculdades" e "Resposta à questão: que é Esclarecimento?" -, colocam o pensamento kantiano sob o signo da estratégia. Não se trata de pensar uma proposta utópica de educação em face da meta final da razão, mas de refletir sobre os passos a serem dados pela universidade em meio à topologia acidentada do poder político, inscrito em uma sociedade concreta. Trata-se, por conseguinte, da reflexão de um homem que expôs suas idéias aos outros cidadãos, que conheceu as exigências da censura não esclarecida, e que procurou pensar a ampliação da esfera pública como um expediente para assegurar um domínio para o exercício progressivamente autônomo e racional do pensamento.

Para perseguir essa reflexão, procuraremos, primeiramente, mostrar a estratégia acadêmica de Kant para assegurar a autonomia da Faculdade de Filosofia. Em seguida, procuraremos expor sua estratégia política para vincular essa autonomia a uma esfera que pudesse expandi-la, assegurando um sentido cosmopolita e esclarecido para o processo de educação da humanidade.

\section{II}

É raro encontrar um escrito em que se manifeste de forma tão intrincada a relação entre poder público, emanado de uma vontade coletiva, e a esfera privada e dirigente da razão. Esta correlação demarca a significação da carreira universitária alemã no séc. XVIII: pôr-se a serviço do Estado ou a serviço da razão. Assim, quem quer se pôr a serviço do Estado deve ingressar nas Faculdades Superiores, ou seja, de Teologia, de Direito, ou de Medicina. Quem quer se pôr a serviço da razão deve manter-se na Faculdade Inferior, a de Filosofia.

Para compreendermos este dúplice papel do intelectual, como Kant o descreve, é preciso antes entender o modo como se organiza a atividade intelectual e sua vinculação ou não com o Estado. Kant classifica a atividade intelectual a partir de quatro atividades básicas: a das Universidades, a das Academias, a dos 
diletantes e a dos funcionários do Estado. Apresentemo-la inversamente, conforme se enquadravam no interior do Estado Prussiano. Os funcionários, por terem um cargo público, estavam diretamente vinculados ao Estado e às suas ordens. Já os diletantes e as Academias organizavam-se à margem das prescrições do Estado. As Universidades, por sua vez, contraíam um vínculo complexo com o Estado. Por um lado, formavam "uma espécie de república de eruditos"1 ("eine Art von gelehrtem gemeinen Wesen" (1983a, CF, IX, A1)², em que os Professores, como depositários de ramos do saber, dividiam-se conforme as especialidades das ciências (Fächer der Wissenschaften). Nesse sentido, recebiam do Estado a incumbência de preparar um grupo de letrados aptos para assumirem e desempenharem funções vinculadas a cargos públicos. Por outro lado, as Universidades tinham a autonomia seja de admitir os alunos que aspiravam a nela ingressar, seja de prover o corpo docente das Faculdades, conferindo-lhes o grau que lhes autorizava o exercício da profissão.

Kant não examinará o caso das Academias e dos diletantes. Deter-se-á nas relações contraídas entre o Estado, as Universidades e os letrados que detêm um cargo público. Estas relações estão plenamente corporificadas na Universidade Prussiana, instituição autônoma academicamente, mas subordinada ao Estado no tocante às doutrinas que devem reger a religião, o direito e a saúde pública. Esta oposição entre autonomia e subordinação manifesta-se na própria divisão entre as Faculdades no interior da Universidade. A Faculdade dita Inferior, que recebia a designação geral de Faculdade de Filosofia, era responsável por um amplo currículo, que envolvia as humanidades em geral $e$ as ciências naturais e físicas

\footnotetext{
${ }^{1}$ Arrimando-se no Deutsches Wörterbuch de Hermann Paul, V. Rohden afirma: "A expressão alemã gemeines Wesen ( = Gemeinwesen) é, justamente no século XVIII, a direta tradução do termo latino res publica (2002, p. 42). Desse modo, V. Rohden propõe a tradução de "gelehrtem gemeinen Wesen" por "república de eruditos" (2002, p. 42). Na tradução francesa que consultamos, essa expressão foi vertida por "estado científico" ("état scientifique") e a tradução portuguesa, segundo V. Rohden,, que consultou o texto proposto por Artur Morão, verte essa expressão por "entidade coletiva erudita". Por iniciativa própria e acolhendo a boa e versátil sugestão de Valerio Rohden, mais adiante, nesse texto, verteremos "bürgerliches gemeines Wesen" por "república de cidadãos".

${ }^{2}$ Doravante serão utilizados as seguintes siglas para a citação dos textos de Kant: CF para $O$ conflito das faculdades, E para "Resposta a questão: que é Esclarecimento?" e OP para "Que significa orientar-se no pensamento?". O texto em alemão foi extraído da edição Weischedel. Desse modo, todas as citações da obra de Kant, aqui apresentadas, contêm a data, a sigla referida, o volume da edição Weischedel e a respectiva página.
} 
teóricas. As Faculdades ditas Superiores, por sua vez, atuavam bem próximas dos desígnios do Estado, subdividindo-se nas Faculdades de Teologia, Direito e Medicina.

É esta divisão e a oposição que ela contém que caracteriza o que Kant nomeia o conflito (der Streit) das Faculdades. Erigidas a partir de fundamentos diferentes, os da razão e os do Estado, a Faculdade Inferior $e$ as Faculdades Superiores abrigam um destino conflitante. Em virtude das tarefas que assumem, as Faculdades Superiores estão destituídas da possibilidade de porem os fundamentos de seu ensino. E esta heteronomia dá-se, segundo Kant, por vários motivos. Primeiro, as Faculdades Superiores não podem fazer uso de um princípio racional para definirem as doutrinas que pretendem ensinar. Suas doutrinas devem estar sempre contidas em um escrito ou livro, que dê estabilidade para certo conjunto de normas que regulam a vida social. Segundo, este escrito, que deve ser regulativo em relação à vida social, tem de ser sancionado pelo governo. Ou seja, é dependente de um órgão externo e superior à Universidade, não podendo ser erigido simplesmente a partir da própria razão (1983a, CF, IX, A15). Terceiro, estas normas, conquanto possam ser examinadas e discutidas, tem de ser obedecidas, porque a autoridade que as sustenta é externa ao saber universitário. Assim, por exemplo, um livro sobre jurisprudência, adotado pelo Professor, guarda valor apenas enquanto organon, ou seja, como instrumento para compreender efetivamente e aplicar corretamente normas cuja autoridade emana de uma instância legislativa, externa à Faculdade de Direito. O teólogo, igualmente, não pode repropor o texto bíblico, mas somente interpretá-lo no interior de alguma religião.

Em oposição às três Faculdades Superiores, de Teologia, Direito $e$ Medicina, a Faculdade de Filosofia, por não cuidar de interesses diretamente vinculados ao Estado, pode atuar com maior liberdade acadêmica e com mais efetivo ânimo de investigação. E isto dá-se por três motivos. Primeiro, não há necessidade de que o ensino por ela ministrado decorra de um texto canônico embora o governo Prussiano exigisse do docente a adoção de um manual para o 
ensino, não prescrevia qual devesse ser adotado ${ }^{3}$. Segundo, a autoridade dos textos aí utilizados repousa em sua inteligibilidade, construída a partir da própria razão. Não estão submetidos, portanto, à exigência de sanção do poder político. Terceiro - e esta é a característica básica desta Faculdade dita inferior -, só a Faculdade de Filosofia tem preservada a liberdade de cátedra.

Isto posto, está dado o conflito: quem atua com liberdade de cátedra e autonomia, tem de forçosamente entrar em confronto com quem não pode fazê-lo, por participar do mundo intelectual sob o signo da heteronomia e da obediência.

Mas este conflito ocorre não somente por causa da subordinação das três Faculdades Superiores ao Estado, mas também em função de sua tarefa, como extensão do braço do Estado, na organização e regulamentação da vida pública. Ao modo de Platão, também Kant descreve a tendência não iluminista da maior parte da população, desejosa por assegurar seja a felicidade após a morte, prometida pelo teólogo, seja a garantia dos seus bens pessoais, personificada no jurista, sejam os prazeres físicos da vida, confiados à atuação do médico (1983a, CF, IX, A30). E o conflito acirra-se ainda mais, segundo Kant (1983a, CF, IX, A3132), na medida em que a população se dirige ao douto como se se voltasse para um profeta ou taumaturgo, apto a fornecer-lhe uma salvação que dispensa todo exame e toda reflexão. Nesse sentido, e como um precursor da crítica dos micro poderes construída por M. Foucault, Kant afirma que cumpre à Faculdade de Filosofia desmistificar o poder da ciência aplicada e do representante estatal que a instrumentaliza no serviço público. Kant indica inclusive, paradoxalmente, que esta é a face anti-iluminista - a dos funcionários investidos com um cargo público por causa de seu saber técnico - que pode voltar-se contra o Estado, pois, se não submetidos ao poder da crítica, estes funcionários podem perverter o poder político em poder técnico, e assim oprimir a população com regras não esclarecidas para a condução da vida pública.

\footnotetext{
${ }^{3}$ Embora isso indique algum grau de liberdade, também não deixa de ser um índice claro do poder de intervenção assegurado ao Estado, sendo efetivamente utilizado por ele. O próprio Kant cumpria essas exigências, utilizando os tratados de Baumgarten para os cursos de Metafísica e Ética, e o tratado de Meier para o curso de Lógica.
} 
Notemos que Kant separa Iluminismo Político e Iluminismo Acadêmico, graduando a relação entre a autonomia política do Estado e a autonomia acadêmica das Faculdades. O Estado deseja regulamentar a vida social e pode fazê-lo de modo esclarecido mediante letrados instruídos para assumir um cargo público. As Faculdades, por sua vez, têm tarefas e autonomias distintas. Às Faculdades de Teologia, Direito e Medicina, por um lado, cumpre o preparo dos que devem ter a instrução exigida para serem investidos de um cargo público. Sua liberdade de pesquisa e de cátedra, portanto, está limitada por sua finalidade. A Faculdade de Filosofia, por outro, por não ter compromissos políticos com o Estado, tem liberdade de pesquisa e de cátedra irrestrita, estando submetida somente à acribia da razão no exame de cada matéria de que trata.

Por isso, a Faculdade de Filosofia tem não só a possibilidade, mas inclusive o dever de pôr sob exame as doutrinas das Faculdades de Teologia, Direito e Medicina. Mas Kant, prudente e estrategista iluminista, não quer laudar o conflito, mas regulamentá-lo. Condiciona-o, assim, com as seguintes regras. Primeiro, não se pode pôr fim a este conflito mediante um acordo amigável, porque o compromisso da Faculdade de Filosofia com a exposição pública da verdade não o permite (1983a, CF, IX, A37-38). Mas ele exige, enquanto processo, uma sentença, que só pode ser dada por um juiz: a razão. Segundo, este conflito é interminável, e cumpre à Faculdade de Filosofia jamais depor as armas da crítica, pois, segundo Kant, "[...] as Faculdades Superiores jamais abdicarão de seu desejo (Begierde) de governar (zu herrschen)" (1983a, CF, IX, A38). Terceiro, este conflito jamais pode ameaçar as bases do Governo. Pois, segundo Kant, não se trata de "[...] um conflito das faculdades com o Governo, mas de uma Faculdade com a outra, ao qual o Governo pode serenamente assistir" (1983a, CF, IX, A38-39). Notemos aqui, novamente, a separação clara entre Iluminismo Acadêmico e Iluminismo Político, pois Kant designa distintamente dois tipos de público: a república de cidadãos (bürgerliches gemeines Wesen) e a república de eruditos (eines gelehrten gemeinen Wesens). Assim, quando um teórico exerce a crítica, deve dirigir-se não à comunidade civil (dos homens de negócios Geschäftsleuten), mas à comunidade acadêmica. Pois sempre há risco, seja para o 
Estado, seja para a comunidade civil, seja para os acadêmicos, quando em público são discutidas doutrinas que têm implicações políticas e cujos fundamentos não são de domínio de todos que terão acesso ao debate. Quarto, a proposta Iluminista kantiana não está destituída de uma meta elevada. Kant afirma que, nestas condições, o conflito pode subsistir, preparando "[...] finalmente a suspensão de todas as limitações da liberdade do juízo público mediante o arbítrio do Governo" (1983a, CF, IX, A42).

Do ponto de vista estratégico, podemos afirmar que há uma heurística política que assegura, a longo prazo, a possibilidade do conflito como fonte de esclarecimento. Dada a impossibilidade de que seja enfrentada diretamente a esfera política - que Kant reconhece como fundada em interesses externos aos da razão -, Kant, no interior da esfera política, demarca a esfera acadêmica e conferelhe imunidade, alegando fazê-lo em benefício do próprio Estado. Assim, posto que heterônomo, cumpre ao Estado instituir a sociabilidade, apresentando as doutrinas que devem entretecê-la nos âmbitos religioso, jurídico, e da saúde pública. Mas Kant prevê que o Estado as apresente não como autor, mas como proponente ideal dotado das melhores intenções; e estas permaneceriam intactas na medida em que o estado submetesse as doutrinas eleitas ao exame das Faculdades, que teriam o encargo de examiná-las e instrumentalizá-las. Assim, ao sancioná-las, o Estado teria preservada sua vontade soberana, pois poderia ter ocorrido que, em parca consonância com sua vontade, os doutores, enquanto funcionários designados pelo Estado, tivessem examinado erroneamente essas doutrinas $e$ as tivessem aplicado incorretamente ${ }^{4}$.

\footnotetext{
${ }^{4} \mathrm{~V}$. Rohden considera que Kant atribui à Filosofia "[...] um lugar especial na tipologia universitária, com uma competência também especial' (2002, p. 49). Essa posição decorre do fato de a Filosofia constituir a essência do exercício autônomo da razão na esfera universitária: "[...] concebe-se a universidade dotada de uma parte dócil à manipulação política, em virtude do grande interesse do povo por seus objetos, mas dotada também de uma outra parte que precisa manter-se armada com armas que ele [Kant] chama de armas da crítica ou de armas da razão - para defender os interesses do conhecimento e da verdade" (2002, p. 48). A reflexão de V. Rohden recupera algo que está bem explícito também no texto de Kant, a saber, o fato de que os interesses imediatos da maior parte da população, voltados para o seu bem estar físico, econômico e espiritual, tornam bastante verossímil o exercício do saber não esclarecido na esfera universitária. Disso decorre a posição fundamental da Faculdade de Filosofia, que deve comportar-se como força lúcida $e$ progressiva da razão esclarecida.
} 
Mas se há ganho político do Governo em assim proceder, com este procedimento também se assegura a esfera (reservada) do juízo acadêmico. Pois o núcleo do saber que se funda a si próprio, ou seja, a Faculdade de Filosofia, desde que cumpra sua função esclarecida no âmbito da esfera acadêmica, mantém sua autonomia no interior da esfera pública. Assim, os acadêmicos não podem intervir diretamente na ordenação pública, instituída por uma vontade coletiva que autoriza o governo. Mas também o governante, mesmo podendo regular a esfera pública, não deve intervir na Academia.

III

Antes mesmo que se manifeste na esfera pública, Kant reivindica o princípio de transparência na esfera privada acadêmica. Trata-se, no entanto, de um princípio burguês, que Kant define como: fazer uso público da própria razão. $\mathrm{O}$ que é este princípio da transparência? Kant reivindica que a vontade do soberano seja racional, ou seja, que ela resista ao exame público. Trata-se de um ato intelectual que, de maneira totalmente nova, procura impor limites racionais progressivos ao exercício do poder político: exigir que, cada vez mais, o fundamento do juízo sobre um ato político-jurídico-econômico-administrativo esteja posto na esfera pública, isto é, que seja publicamente autorizado somente o que puder ser examinado pela razão (instituída na esfera pública).

No entanto, quanto mais racionalizada for a esfera pública, enquanto esfera do juízo autônomo, tanto menor torna-se a possibilidade do exercício arbitrário do poder. Neste sentido cabe a pergunta: ao pôr-se no processo de Esclarecimento, cumpre ao homem libertar-se de toda autoridade tutelar? Esta questão não é respondida diretamente por Kant, e ela encerra a dificuldade justamente de quem lê o texto sobre a "Resposta à questão: que é Esclarecimento?". Qual dificuldade? A principal, aquela que se apresenta claramente formulada pelo construtor de paradoxos de Königsberg, quando declara: critique, mas obedeça. Para não tomar este paradoxo por uma aporia, é preciso separar as esferas em que estes atos ocorrem e conceber como elas podem correlacionar-se idealmente. 
Kant caracteriza o Esclarecimento como a passagem da menoridade para a maioridade, alcançada pela decisão do homem de pensar por si próprio. Menoridade e maioridade podem aqui ser entendidas, respectivamente, como ato de obedecer a um superior e ato de obedecer à razão. No primeiro caso, o homem delega, senão o poder de pensar, ao menos o poder de decidir a um outro; no segundo caso, o homem assume sua própria razão como fundamento da decisão. Estes dois atos vinculam o homem a duas esferas distintas, caracterizadas, respectivamente, pela heteronomia e pela autonomia.

Ora, se a liberdade conduz ao Esclarecimento ${ }^{5}$, e se o Esclarecimento realiza-se pela passagem da menoridade à maioridade, então põe-se a seguinte questão: é forçoso que, ao esclarecer-se, o homem rompa com todos os vínculos que o dominam heteronomamente, e passe a agir de forma exclusivamente autônoma? ${ }^{6}$ Por certo que isto não poderia ocorrer exatamente assim, porque significaria a submissão da Política à Filosofia, ou do poder à razão, alternativa examinada por Platão num livro denominado $A$ República. Kant aqui reconhece as dificuldades da razão esclarecida em face da realidade política não esclarecida da Alemanha, e atua como um estrategista, regulando o conflito com vistas a preservar a especificidade de cada esfera. Kant então estabelece a relação entre duas esferas: a da obediência autônoma e a da obediência heterônoma. O exercício da crítica, portanto, é decorrência da obediência autônoma, na medida em que o homem decida pensar por si próprio e agir em conformidade com sua

\footnotetext{
${ }^{5}$ Kant afirma que "para esse esclarecimento nada é exigido a não ser liberdade [...]"(1983b, E, IX, A484). Imediatamente na seqüência, para tornar esse projeto compatível com a situação política em que ele se insere, Kant, de modo bastante irônico, qualifica essa liberdade por um superlativo, "a mais inofensiva (unschädlichste) de todas" - ele diz -, a saber, a liberdade de "fazer uso público da própria razão" (1983b, E, IX, A484).

${ }^{6}$ Kant jamais pensa o projeto do esclarecimento como uma resultante de indivíduos que progridem de forma atomizada na sociedade civil. C. M Pinheiro, em relação a isso, nos lembra de algo muito importante: "sabemos que Kant afirma em seu texto: Resposta à pergunta: o que é esclarecimento, que o homem é um ser inicialmente guiado pela preguiça e covardia, condições que o colocam numa situação de menoridade. Sair desse estado e buscar o esclarecimento constitui tarefa de cada indivíduo. Mas, o abandono desse estado é em prol da humanidade inteira e não apenas para seu próprio proveito e gozo. O indivíduo é suplantado pela espécie" (2007, p. 36 - grifo nosso). No entanto, para que esse projeto deixe de ser infrutiferamente individual $e$ passe a ser efetivo $e$ coletivo - o que é o tema da presente reflexão - há a necessidade de uma intrincada mediação entre as esferas da sociedade civil, da universidade e do poder político. Se olharmos o problema por essa perspectiva, o texto de Kant torna-se dramático, porque o autor tem então de ser concebido não simplesmente como um professor, mas como um arguto e cuidadoso estrategista.
} 
própria razão. No entanto, Kant afirma que a esfera da eficácia prática da razão esclarecida tem de ser limitada em benefício dela própria, ou seja, não há vínculo imediato entre pensar de modo esclarecido e agir de modo esclarecido. Isto pode parecer paradoxal, mas Kant está afirmando o seguinte: para que a liberdade de pensar mantenha sua máxima abrangência, é preciso que seja restringida a liberdade civil. Kant afirma isto explicitamente:

Então mostra-se aqui um estranho $e$ não esperado percurso das coisas humanas; do mesmo modo como, se se o considera no todo, quase tudo nele é um paradoxo. Um grau mais elevado de liberdade civil parece ser vantajoso à liberdade de espírito do povo, e, no entanto, estabelece para ela barreiras intransponíveis; um grau menor daquela, inversamente, dá a esse espaço a possibilidade de expandirse em conformidade com toda a sua capacidade (1983b, E, IX, A493).

Vertamos de modo claro o conteúdo cuidadosamente implícito deste texto: quanto maior for a liberdade civil, maior será a possibilidade de a liberdade de pensar produzir conseqüências práticas; em decorrência disso, mais intensa virá a ser a vigilância do soberano sobre a liberdade de pensar, com vistas a evitar desvios de conduta indesejáveis que possam colocar em risco o organismo social. Inversamente, quanto mais restrita for a liberdade civil e quanto mais seguro for o controle sobre a conduta individual, mais ampla poderá ser a liberdade de pensar, pois menores serão os riscos de que ela produza conseqüências práticas imediatas e indesejáveis do ponto de vista do serviço público.

Em face destas correlações, caberia então perguntar: desejaria Kant um Esclarecimento sem conseqüências práticas? Por certo que não, mas é igualmente verdadeiro que não desejaria um Esclarecimento com conseqüências práticas imediatas. Kant reconhece que as esferas do uso público e do uso privado da razão não podem correlacionar-se diretamente, sob o risco da primeira produzir disfunções na segunda, e da segunda, reativamente, restringir o círculo de atuação da primeira. Podemos discordar, mas a estratégia kantiana é intencionada e paradoxal: restringir cuidadosamente a liberdade de conduta na esfera do uso 
privado da razão, para expandir ao máximo a liberdade de pensar na esfera do uso público da razão. O quanto esta estratégia é intencionada, pode ser estimado a partir da seguinte afirmação, em que, após constatar que no uso privado da razão a obediência é exigida como norma de conduta, Kant conclui: "Por toda parte há aqui restrição da liberdade. Mas qual restrição causa impedimento ao Esclarecimento? Qual não causa, mas até mesmo o promove (beförderlich)?" (1983b, E, IX, A484). À primeira pergunta, Kant responde que a impossibilidade de fazer uso público da razão geraria o principal obstáculo ao Esclarecimento, ameaçando-o radicalmente. Assim, qualquer restrição à liberdade de pensar por si poria em risco a atitude que dá sustentação à maioridade. À segunda pergunta, Kant responde: "[...] o uso privado da razão pode porém muitas vezes ser muito estreitamente restringido (eingenschränkt sein), sem com isto impedir particularmente o progresso do Esclarecimento" (1983b, E, IX, A485). Retornemos literalmente à questão formulada. Kant indagava qual restrição à liberdade não impede, mas até mesmo promove o Esclarecimento. Da pergunta e da resposta, podemos então aduzir que a restrição da liberdade no uso privado da razão não impede mas promove o Esclarecimento, na medida em que, sem oferecer riscos imediatos para uma dada organização da sociedade, possibilita a expansão do uso da razão na esfera pública. Desse modo, se o Esclarecimento for compreendido como um processo de educação da humanidade, a esfera pública representa o domínio em que todos os seres humanos se educam mutuamente. Trata-se, então, do progresso de uma esfera autônoma, aberta à participação de todos, e que, por estar circunscrita ao exercício público da razão, deve permanecer livre da intervenção e do arbítrio estatal.

\section{IV}

Kant reconhece, assim, que a esfera do uso privado da razão, porque funcional e, em decorrência, heterônoma, é improfícua para a ampliação do Esclarecimento. Isso implica que o Esclarecimento deve ser concebido como um processo, e não como um estágio, e que ele tem de ser conquistado ativamente, não podendo ser de modo algum passivamente concedido. Posto que o conceito 
de Esclarecimento tem determinações tão paradoxais, chegamos então ao fecho destas reflexões, que pode ser colocado por meio da seguinte questão: como entender o conceito de Esclarecimento?

Primeiro, é preciso observar que Kant diverge largamente da tradição que inclusive o sucedeu. O Esclarecimento, aqui, não é alcançado pela produção e acúmulo de conhecimentos científicos. O próprio Kant afirma que "[...] quase sempre, aquele que é sobremaneira rico em conhecimentos, é minimamente esclarecido no uso dos mesmos" (1983c, OP, V, A330). Trata-se, pois, de uma atitude fundada na razão, e não de um acúmulo de conhecimentos produzidos pelo intelecto. Nesse sentido, ao separar acúmulo de conhecimentos e reflexão autônoma, Kant retira o Esclarecimento do âmbito da ciência e o coloca como um processo de educação da humanidade.

Segundo, para entender o conceito de Esclarecimento, é preciso separar a esfera do uso privado da razão da esfera de seu uso público. A esfera do uso privado é aquela em que o jurista interpreta as leis, o teólogo faz exegese da Bíblia e o médico atende às normas da saúde regulamentada pelo Estado. A esfera do uso público da razão, por sua vez, é aquela em que cada ser humano se torna educador de todos ou outros homens, justamente quando torna a razão o fundamento do juízo acerca das questões fundamentais da vida civilizada. Da esfera do uso público também podem fazer parte aqueles profissionais - o jurista, o teólogo, o médico, etc. -, desde que façam abstração dos cargos com que foram investidos $e$ dos poderes que lhes foram conferidos, $e$ se dirijam aos outros cidadãos somente com a autoridade que lhes confere o uso público de sua própria razão. Ou seja, desde que se dirijam aos outros cidadãos com o interesse simultâneo de ensinar e aprender tudo aquilo que diz respeito ao uso autônomo da razão.

Terceiro, também não é qualquer ampliação da liberdade que favorece o Esclarecimento. Neste ponto, o texto kantiano enfrenta um desconfortável paradoxo. Kant sustenta que o Esclarecimento pode conviver com restrição da liberdade, desde que ela ocorra apenas na esfera do uso privado da razão. Mais do que isto, Kant afirma que a restrição da liberdade na esfera do uso privado da 
razão pode inclusive promover o Esclarecimento, na medida em que não há fundamento então para se opor qualquer objeção de cunho político à norma da liberdade de pensar.

Neste sentido, respondamos à questão que abriu e conduziu estas reflexões, a saber: ao pôr-se no processo de Esclarecimento, cumpre ao homem libertar-se de toda autoridade tutelar? As reflexões aqui apresentadas indicam que isto deva ocorrer, mas jamais diretamente e sim mediante uma intrincada mediação. Kant intenta fundar a esfera do esclarecimento em meio à esfera não esclarecida da autoridade política e das relações de poder que ela concentra. Assim, Kant vale-se de uma república de cidadãos - que passa a ser nomeada com confiança -, o público, com vistas a transferir-lhe não a autoridade de governar, mas a de pensar. A esfera do Esclarecimento, portanto, que contém o que o seu conceito possibilita, é constituída: primeiro, por uma atitude, daquele que se propõe a pensar por si próprio; segundo, na medida em que este, procedendo a partir deste fundamento, se dirige a outros, construindo assim a esfera efetiva do uso público da razão; terceiro pela ampliação irrestrita desta possibilidade de fazer uso público da razão, desde que seja aceito, no curto prazo, que isto não pode produzir conseqüências políticas imediatas na sociedade civil.

A idéia reguladora deste texto, por conseguinte, é a de que o Esclarecimento deve ser entendido como um processo de educação da humanidade. Mas esse processo deve se orientar, de modo arquetípico, pelas idéias de emancipação e autonomia. Portanto, a educação não deve pressupor somente um processo técnico de aquisição de conhecimentos, que favoreçam a socialização do ser humano, mas deve orientar-se igualmente pelo desenvolvimento da capacidade de fazer uso próprio da razão na esfera pública. Desse modo, entendido como um processo de educação da humanidade, o Esclarecimento deve estabelecer estratégias de convivência com a esfera do uso privado da razão, iluminando, a longo prazo, a esfera não esclarecida que o possibilitou e em meio à qual nasceu. 


\section{Referências}

KANT, Immanuel. Der Streit der Fakultäten. In: Werke in zehn Bänden. 5. Aufl. Hrsg. von Wilhelm Weischedel. Darmstadt: Wissenschaftliche Buchgesellschaft, 1983a. Bd. 9.

. Le conflit des facultés. Traduit par J. Gibelin. Paris: Vrin, 1997.

. Beantwortung der Frage: was ist Aufklärung. In: Werke in zehn

Bänden. 5. Aufl. Hrsg. von Wilhelm Weischedel. Darmstadt: Wissenschaftliche Buchgesellschaft, 1983b. Bd. 9.

. Resposta à pergunta: que é "esclarecimento"? In: Immanuel Kant: textos seletos. Tradução de Floriano de Sousa Fernandes. Petrópolis: Vozes,1974. . Was heisst: sich im Denken orientieren? In: . Werke in zehn

Bänden. 5. Aufl. Hrsg. von Wilhelm Weischedel. Darmstadt: Wissenschaftliche Buchgesellschaft, 1983c. Bd. 5.

. "Que significa orientar-se no pensamento?" In: A paz perpétua $e$ outros opúsculos. Tradução de Arthur Morão. Lisboa: Edições 70, 1990. LOSURDO, D. Autocensure et compromis dans la pensée politique de Kant. Traduit par Jean-Michel Buée. Paris: Presses Universitaires de Lille, 1993. PINHEIRO, Celso de Moraes. Kant e a educação: reflexões filosóficas. Caxias do Sul/RS: Educs, 2007.

ROHDEN, Valerio. Autonomia da universidade na perspectiva da filosofia política de Kant. In: (org.). Idéias de Universidade. Canoas: Editora da Ulbra, 2002. 